movement causing him extreme breathlessness, but on the other hand while lying flat on his back and remaining quiet he had no pain and the urgency of the breathing was relieved. This made him hope that the attack would pass off. On Sunday, however, I was sent for. He was up when I saw him and his condition was as follows. While he was lying quite still there was not much apparent distress, his respirations being 32 per minute, bis pulse 124, and his temperature $97 \cdot 8^{\circ} \mathrm{F}$. He was a healthy-looking young fellow, 5 feet $10 \frac{1}{2}$ inches in height, well nourished and muscular, and weighed 11 stones 6 pounds. On examining his chest no movement of the chest walls was observable on the left side and the intercostal spaces were widely distended. On palpation no vocal fremitus could be obtained either in front or behind and the percussion note on that side was so absolutely dull and muffled in tone as to make me at first believe that the left pleural cavity contained fluid. The dall note extended evenly all over the front and back and no heart impulse was anywhere on that side observable. On auscultation no breath sounds or vocal fremitus could be heard at the back or front, but at or about the fifth intercostal space in front there was to be heard on inspiration a peculiar metallic sound which it is difficult to describe accurately, but which re. sembled in a marked degree the peculiar metallic spring-like noise which is made by my collar stud (which has a moveable head on a spring attachment) when I move my head. This sound, I may here remark, ceased on the third day of my attendance and was, I suppose, due to the escape of a minute bubble of air from the valvular opening in the lung and its bursting in the pleural cavity. On examining the right side of the chest the heart apex was discovered at a point in the fifth interspace about one inch beyond the right border of the sternum. Over and around this position the heart sounds were fairly audible. With this exception the physical signs on the right side were normal, the dividing line between the two pleural cavities being easily mapped out by the percussion note and the presence and absence of rocal res onance. The bruit d'airain was absent. The patient was simply kept quiet in bed for the first fortnight. He had no pain or dyspncea and he slept and ate well. On the third day of my attendance the extreme distension of the left side had lessened perceptibly and the percussion note for the first time became markedly hyperresonant all over, including, of course, that portion of the left side usually occupied by the heart. From the first he gradually got better; the heart beats lessened in frequency, the tension in the chest lessened, the heart gradually moved over to its proper position, and the breath sounds returned, first at the apex in front and then gradually lower and lower; the difference in the vocal resonance on the two sides became less and less marked as the lung became less compressed by the absorption of the contained air until at the end of eight and a half weeks (April 28th), when I examined him carefully before letting him go for change of air prior to going back to work, no abnormal symptom could be discovered. He never at any time had any cough. His temperature never rose above normal and $I$ was never at any time auring the illness able to discover any physical signs of fluid in the pleural cavity. In fact, his recovery was uninterrupted. He returned to work after a fortnight's change well and strong.

With regard to the cause of this accident, although an interval of some hours elapsed between what was the apparent cause and the effects, yet there is no doubt in my mind that the blow or weight on the chest by the ledgers was the direct cause. The leakage of air was so very gradual, the opening being minute and probably valvular, that it is impossible to say at what moment physical signs could have been discovered if they had been looked for. Distress did not arise until compression of the lung had become extreme. It has been argued by the office in which he was insured that he ought to have felt the symptoms sooner, but when in bed lying quietly on his back he never during the whole course of his illness had the slightest pain, distress, or dyspnœa, so that physical signs probably existed long before they were apparent to him. With regard to the mode of causation, we have first a deep inspiration filling out the chest cavity to the lung's utmost capacity and closure of the glottis, the lower edge lying between the chest wall behind the sixth rib and the firmly contracted diaphragm. Suddenly the patient has a smart blow from the heap of ledgers falling on to his chest wall, bending in the sixth rib, and possibly nipping or forcibly compressing the edge of the lung and rupturing a minute air vesicle. M. Gosselin even says that the prolonged compression of the over-distended lung will cause it to give way, the glottis being tightly closed. The analogy has been suggested of a bit of the inner tube of a bicycle being accidentally nipped between the wire of the outer casing and the rim of the wheel when not properly returned after mending a puncture, \&c., and rupturing the tube directly the rider mounts and puts pressure on the tabe. It has been suggested, too, that in most if not all of these cases of pneumothorax occurring in the apparently healthy some previous disease, probably tuberculous softening, has conduced to bring about the result Here we have no family or previous personal history which would lead one to suspect it, and the complete recovery of the patient tends to nullify any such supposition; besides which the history of the accident would to $\mathrm{my}$ mind be quite sufficient to account for the damage to the lung without there being any necessary previous disease, while finally the absence of any effusion or pleurisy tends to confirm $\mathrm{my}$ contention of its absence.

West Kensington, W.

\section{PTOMAINE POISONING FOLLOWED BY DESQUAMATION.}

By Percy T. Goodman, L.S.A. Lond.

ON May 20th, 1904, I was called in the early morning to a family of seven persons who had all partaken of a fish supper on the previous evening. They were in a state of collapse, with pallid faces, clammy perspiration, and cold extremities, and were complaining of severe abdominal pain and vomiting. In two cases diarrhoea was present with very offensive stools. There was no urticaria or rash of any description. None of the family had any rise of temperature or sorethroat. Warmth was applied to the extremities and a purgative was given followed by stimulants (ammonia and ether). All the patients recovered and I saw nothing more of them until June 1st when the mother brought one of her boys to me on account of his school teacher having sent him home because of the condition of his hands and feet from which the skin was coming off, chiefly on the palmar surface, in large flakes. The mother also had some slight desquamation on the forearms. I went to the house and saw the other children whose ages ranged between seven and 16 years, all of whom had the same curious desquamation on the palms of the hands and the soles of the feet. The father alone was not affected in this manner.

I have heard of one other similar case which occurred in the practice of my friend Dr. J. Snowman of Brondesbury, but I do not remember having anywhere read an account of this remarkable condition after food poisoning. The points of interest in these cases lie in their strong resemblance to post-scarlatinal desquamation and in the fact that six of the seven persons who suffered from ptomaine poisoning developed this unusual sequela.

Spitalfields, $\mathbf{E}$.

\section{SEQUEL TO A OASE OF INOPERABLE CANOER} TREATED BY OÖPHORECTOMY.

By WaLTer EDMUNds, F.R.C.S. ENG., SURGEON TO THE TOTTENHAM HOSPITAX.

IN THE LANCET of March 29th, 1902, at p. 888 is recorded a case of scirrhus of the breast in which symptoms of intrathoracic growth appeared five years after amputation. There was also a recurrence in the remaining breast. Oöphorectomy and thyroid feeding were had recourse to, with the result that at the time of the report, a year after the operation, the patient was much better. The tumour in the breast and axillary glands had almost disappeared and the dvspncea, too, had nearly gone. The further history of the case is that nine months later the patient was not so well : the tumour in the breast had somewhat increased and was commencing to involve the skin; the dyspnœa, too, was somewhat worse. Three months later the skin over the tumour had ulcerated and on this account it was thought advisable to amputate the breast. Unfortunately the patient died from heart failure while under the anæsthetic. An 
account of this part of the case has already been placed on record by the anæsthetist. ${ }^{1}$

A post-mortem examination was made by Dr. L. Freyberger at which he invited me to be present. The right breast was as described; there were also enlarged glands in the axilla and recently infiltrated glands in the flank. At the bifurcation of the trachea was a mass of secondary growth involving the roots of the lungs. The left lung was bound to the chest wall by old adhesions, the aorta was atheromatous, and the heart had undergone some fatty degeneration. Although the oöphorectomy did not save the patient's life it produced for a time great benefit; the tumour in the remaining breast almost disappeared, while the small growth behind the ear did completely disappear; the symptoms due to the intrathoracic growth were also greatly relieved. In this case then, as in many others, much good was done by the operation. In conclusion, it may be pointed out that any theory as to the pathology of cancer must explain the improvement effected by oöphorectomy in recurrent scirrhus of the breast.

Devonshire-place, $W$.

\section{A extiturt}

\section{HOSPITAL PRAOTICE, BRITISH AND FOREIGN.}

Nulla autem est alia pro certo noscendi via, nisi quamplurimas et morborum et dissectionum historias, tum aliorum tum proprias collectas habere, et inter
Morb., lib. iv., Procmium.

\section{GREAT NORTHERN CENTRAL HOSPITAL.}

A CASE OF SARCOMA OF THE PLEURA AND LUNG WITH CONSEOUTIVE PERICARDITIS AND GROWTH IN BRAIN

AND PANCREAS, PRESENTING UNUSUAL CLINICAL FEATURES

(Under the care of Dr. H. W. Syers.)

THE patient, a man, aged 31 years, married, wasadmitted into the Great Northern Central Hospital on Sept. 3rd, 1903, complaining of pain in the abdomen, headache, and malaise. He was in his usual health until the last week of the previous April, when he complained of feeling giddy from time to time. On May 14th he fell a distance of four feet on to a mound of soft earth. From this time onwards he complained of headache, backache, and of pain over the upper portion of the abdomen. At the beginning of June he first noticed that his eyesight was not so good as formerly and on several occasions he "saw double." At the same time some slight swelling of the face was noticed. There had keen no swelling of the lower extremities or under the eyes; no vomiting, shortness of breath, cough, or jaundice had been complained of. Seven years before the patient suffered from rheumatism but the illness did not seem to have been serious. One and a half years before admission he had an attack of pleurisy affecting the left side, but was in bed one day only. There was no history of "fits" and none of alcoholism. Apart from the maladies mentioned he always appeared to have had very good health and there was no history of syphilis. The family history was unimportant. The patient was thin and rather pale. He complained of headache, not localised, and of failing eyesight, together with more or less generalised and indefinite pain, which was not, bowever, severe. The temperature was normal, the pulse was 96 , and the respirations were 24 ; the tongue was clean. The lungs were healthy, except that at the left base there was dulness on percussion, extending nearly to the angle of the left scapula, and over the dull area the breath sounds were very feebly audible. The vocal resonance and vocal fremitus were both greatly diminished. In fact, there were the ordinary signs of a moderate pleural effusion at the left base. No adventitious sound could be detected in this locality. The heart was acting in an extremely forcible manner, so much so that the heart impulse, which was greatly diffused, could be seen at some distance from the bed and this even when the bedclothes

1 Transactions of the Society of Anæsthetists, vol. vi., p. 66, 1903. were stretched over the chest as the impulse was sufficiently vigorous to raise them. The maximum impulse was in the fifth interspace and in the nipple line. No thrill could be detected on palpation. There was no murmur at the apex, but a rough systolic murmur could be detected at the second left interspace close to the sternum. The carotids did not pulsate unduly. Examination of the abdomen, and more especially of the epigastric region, revealed nothing abnormal. There was no paralysis, either general or special. Both knee-jerks were absent. A flexor plantar reflex could be obtained. These was no anæsthesia anywhere. The gait was somewhat unsteady and when he stood with eyes closed and feet together he began at once to stagger. There was slight undue prominence of the right eye but it was not certain that this had not always been the case. The pupils were equal and acted both to light and accommodation. There was no special peculiarity as regards speech. Most marked double optic neuritis was present, the lesion being especially prominent on the left side. The urine had a specific gravity of 1010 ; it was acid and contained neither albumin nor sugar.

On Sept. 8th it was reported that the patient had been restless and uneasy, especially at night. At times he seemed to lose conzciousness momentarily and occasionally for longer periods. While unconscious he fell out of bed on two occasions. There was complete control of the sphincters. The violent action of the heart continued and was indeed more marked; the pulse-rate varied from 80 to 90 . There were no fresh physical signs on auscultation either of the heart or lungs. On the 9th the condition was unchanged, except that the patient was less restless. The tendency to lose himself mentally was less marked. On the 14th a loud, harsh, pericardial friction sonnd was detected, loudest at the base and down the right margin of the sternum. There was no pain in the præcordial region and the temperature remained practically normal. On the 15th there was very obvious pericarditis; the apex beat was felt in the fifth interspace, half an inch internal to the nipple; it was diffuse and very forcible, raising the chest wall. No thrill could be detected. The dulness at the base of the left lung had now become absolute, and over this area the heart sounds were heard with unnatural clearness. The breath sounds were now completely absent over the dull area which extended upwards almost to the root of the lungs. The knee-jerks were still absent and irritation of the soles of the feet caused no extension of the toes. There was no paralysis or even paresis and no anæesthesia could be made out. The pupils remained equal and active both to light and accommodation.

The patient's mental conditicn now showed a change. He had been throughout rather silent and indifferent as to his condition, but by this time, although perfectly intelligent and readily responding when spoken to, he manifested a marked loss of initiative. He never asked for anything, showed no likes or dislikes, and made no complaint of any kind. He was not dull or lethargic, for when addressed he invariably answered clearly and to the point. The optic neuritis was, if anything, still more marked but he could see to read, though he never read a book or a paper voluntarily, remaining perfectly quiet in one position for hours together. On Sept. 19th it was noticed that the right eye was slightly more prominent than the left. The pericarditis persisted, the double friction sound being very well marked; the cardiac dulness now extended to the right border of the sternum. Nothing abnormal could be detected on examination of the abdomen, but during the next few days there were some pain after eating and flatulent distension. On the 24th he complained of severe pain in the upper portion of the abdomen, the pain extending through to the back. The pain prevented him lying down in an easy posture. He was now getting thin and the expression was worn and anxious. On the 28th the abdominal pain continued. The dnlness over the left base was now increasing both vertically and towards the lateral region. On this day and on a previous occasion an exploring needle was passed into the area of dulness, but neither fluid nor pus was withdrawn. On the second occasion some bright red blood entered the cavity of the syringe, but a small quantity only. On the 29th the cardiac dulness was increased in all directions, extending upwards to the left clavicle and one and a half inches beyond the right border of the sternum, and at the same time the friction sound disappeared, except at the left base, 